\begin{abstract}
Iranica
Abstracta Iranica Revue bibliographique pour le domaine irano-aryen

Volume 34-35-36 | 2017

Comptes rendus des publications de 2011-2013
\end{abstract}

\title{
Maciej Grabowski. Ardasir's Struggle Against the Parthians. Towards a Reinterpretation of the Firuzabad I Relief
}

\section{Julien Cuny}

\section{(2) OpenEdition}

Journals

Édition électronique

URL : http://journals.openedition.org/abstractairanica/42307

DOI : 10.4000/abstractairanica.42307

ISSN : 1961-960X

Éditeur :

CNRS (UMR 7528 Mondes iraniens et indiens), Éditions de l'IFRI

Référence électronique

Julien Cuny, «Maciej Grabowski. Ardasir's Struggle Against the Parthians. Towards a Reinterpretation of the Firuzabad I Relief », Abstracta Iranica [En ligne], Volume 34-35-36 | 2017, document 34, mis en ligne le 30 juillet 2017, consulté le 26 septembre 2020. URL : http://journals.openedition.org/ abstractairanica/42307 ; DOI : https://doi.org/10.4000/abstractairanica.42307

Ce document a été généré automatiquement le 26 septembre 2020.

Tous droits réservés 


\section{Maciej Grabowski. Ardasir's Struggle Against the Parthians. Towards a Reinterpretation of the Firuzabad I Relief}

Julien Cuny

\section{RÉFÉRENCE}

Maciej Grabowski. « Ardasir's Struggle Against the Parthians. Towards a

Reinterpretation of the Firuzabad I Relief ». Iranica Antiqua, 46, 2011, p. 207-233.

1 Les scènes de combat représentées sur le premier relief rupestre commandité par Ardašīr $\mathrm{I}^{\mathrm{er}}$ seraient selon l'A. une représentation synthétique des trois étapes principales de la conquête du pouvoir par la nouvelle dynastie. Partant de ce postulat, il propose une nouvelle identification, assez convaincante, de certains personnages à partir d'une relecture de l'ensemble des sources traitant de la conquête et des données numismatiques.

\section{AUTEURS}

JULIEN CUNY

Musée du Louvre 